\title{
Reliability Improvement Strategies for HVDC Transmission System
}

\author{
Yidong Hong, Tao Yu \\ Institute of Power, South China University of Technology, Guangzhou, China \\ Email: hongyidong1989@126.com
}

Received 2013

\begin{abstract}
This paper analyses reliability data of HVDC systems of Southern China Power Grid. The weak links of HVDC systems' operational reliability are DC control and protection, valve hall and valve cooling system and transmission lines. Some improvement measures and HVDC system reliability technology are proposed in this paper.
\end{abstract}

Keywords: HVDC; Transmission; Operation; Reliability

\section{Introduction}

HVDC Transmission has obvious advantages in the respect of long distance transmission on a large scale and interconnection of power systems. It's significant for west-east power transmission and national interconnection of power systems in China. The reliability in HVDC systems indicates the amount of power transmitted in specified time, conditions and environment. [1] Data shows that the availability rate of operating HVDC systems is over 90 percent. It has been proposed in InterMountain HVDC system that reliability level of bipolar HVDC should be higher than double-circuit AC lines. More requirements are raised for the reliability of HVDC systems with the technology of HVDC developing and more real projects go into operation. The improvement of reliability would bring great benefits to the safe, reliable and economic operation of the systems. Thus, reinforcing the work of analysis about reliability indices and management of reliability is good for searching the weak links and influencing factors of reliability scientifically. Taking measures to improve HVDC systems reliability can guarantee the secure and available operation of HVDC systems.

\section{Analysis of Reliability Indices of HVDC Systems}

Statistics of HVDC transmission systems include converter transformers, converter valves, AC filters, capacitor, and DC filers, smoothing reactor, transmission lines and control protection devices. While failure types in
HVDC systems are various and complex, they can be classified into six types: AC and its device, Converter Valve, DC control and protection, primary equipments, transmission lines and others. [2-3]

Failures in HVDC systems have a great influence on operating reliability so that reliability indices are influenced directly or indirectly. Through statistics and analysis of reliability indices of Tianguang, Gaozhao, Xingan and Chusui HVDC systems during 2005 to 2011, it's obvious that DC block have a great impact on safe and reliable operation of HVDC systems. So the reasons that may cause DC blocks are analyzed and classified specifically.

It's shown in the statistics and classification of causes of DC blocks that monopole block and bipolar blocks are both mainly caused by failures in primary equipments, control and protection system, valve hall and valve cooling system, transmission lines and AC protection. According to statistics, there are 110 DC blocks during 2005 to 2011 in these four HVDC systems. The causes leading to DC blocks are 6 times of primary equipments, 48 times of DC control and protection, 18 times of valve cooling systems,37 times of transmission lines and 1 time of AC protection. They account for 5.45 percent, 43.64 percent, 16.36 percent, 33.64 percent, and 0.91 percent separately as is shown in Figure 1.

From Table 1 and Figure 1, it's shown that measures should be taken to improve operating reliability of HVDC system. According to the distribution of causes of DC blocks in daily operation, this paper focuses on DC control protection and valve hall and valve cooling system to improve operation reliability of HVDC systems. 
Table 1. Statistics and Classification of Causes of HVDC Systems' Blocks.

\begin{tabular}{|c|c|c|c|c|c|c|c|c|c|}
\hline HVDC System & Block Reasons & 2005 & 2006 & 2007 & 2008 & 2009 & 2010 & 2011 & Sum \\
\hline \multirow{7}{*}{ Tianguang HVDC System } & Monopole Block（Times） & 5 & 7 & 10 & 5 & 1 & 3 & 2 & 33 \\
\hline & Bipolar Block（Times） & 1 & 1 & 3 & 0 & 0 & 0 & 0 & 5 \\
\hline & Primary Equipment & 1 & 0 & 0 & 0 & 0 & 0 & 0 & 1 \\
\hline & Control and Protection Equipment & 1 & 1 & 10 & 4 & 1 & 1 & 1 & 19 \\
\hline & Valve Hall and its Cooling System & 1 & 4 & 0 & 1 & 0 & 0 & 1 & 7 \\
\hline & Transmission Lines & 3 & 2 & 3 & 0 & 0 & 2 & 0 & 10 \\
\hline & AC Protection & 0 & 1 & 0 & 0 & 0 & 0 & 0 & 1 \\
\hline \multirow{7}{*}{ Gaozhao HVDC System } & Monopole Block（Times） & 6 & 8 & 5 & 7 & 5 & 3 & 4 & 38 \\
\hline & Bipolar Block（Times） & 0 & 1 & 1 & 0 & 0 & 0 & 0 & 2 \\
\hline & Primary Equipment & 0 & 1 & 1 & 0 & 0 & 1 & 0 & 3 \\
\hline & Control and Protection Equipment & 2 & 6 & 2 & 2 & 2 & 0 & 2 & 16 \\
\hline & Valve Hall and its Cooling System & 3 & 1 & 0 & 1 & 1 & 0 & 1 & 7 \\
\hline & Transmission Lines & 1 & 1 & 3 & 4 & 2 & 2 & 1 & 14 \\
\hline & AC Protection & 0 & 0 & 0 & 0 & 0 & 0 & 0 & 0 \\
\hline \multirow{7}{*}{ Xingan HVDC System } & Monopole Block（Times） & --- & --- & --- & 8 & 5 & 6 & 1 & 20 \\
\hline & Bipolar Block（Times） & --- & --- & --- & 4 & 0 & 0 & 0 & 4 \\
\hline & Primary Equipment & --- & --- & --- & 1 & 0 & 1 & 0 & 2 \\
\hline & Control and Protection Equipment & --- & --- & --- & 4 & 4 & 2 & 2 & 12 \\
\hline & Valve Hall and its Cooling System & --- & --- & --- & 1 & 0 & 1 & 1 & 3 \\
\hline & Transmission Lines & --- & --- & --- & 6 & 1 & 2 & 1 & 10 \\
\hline & AC Protection & --- & --- & --- & 0 & 0 & 0 & 0 & 0 \\
\hline \multirow{7}{*}{ Chusui HVDC system } & Monopole Block（Times） & --- & --- & --- & --- & --- & 2 & 3 & 5 \\
\hline & Bipolar Block（Times） & --- & --- & --- & --- & --- & 0 & 0 & 0 \\
\hline & Primary Equipment & --- & --- & --- & --- & --- & 0 & 0 & 0 \\
\hline & Control and Protection Equipment & --- & --- & --- & --- & --- & 1 & 0 & 1 \\
\hline & Valve Hall and its Cooling System & --- & --- & --- & --- & --- & 0 & 1 & 1 \\
\hline & Transmission Lines & --- & --- & --- & --- & --- & 1 & 2 & 3 \\
\hline & AC Protection & --- & --- & --- & --- & --- & 0 & 0 & 0 \\
\hline
\end{tabular}

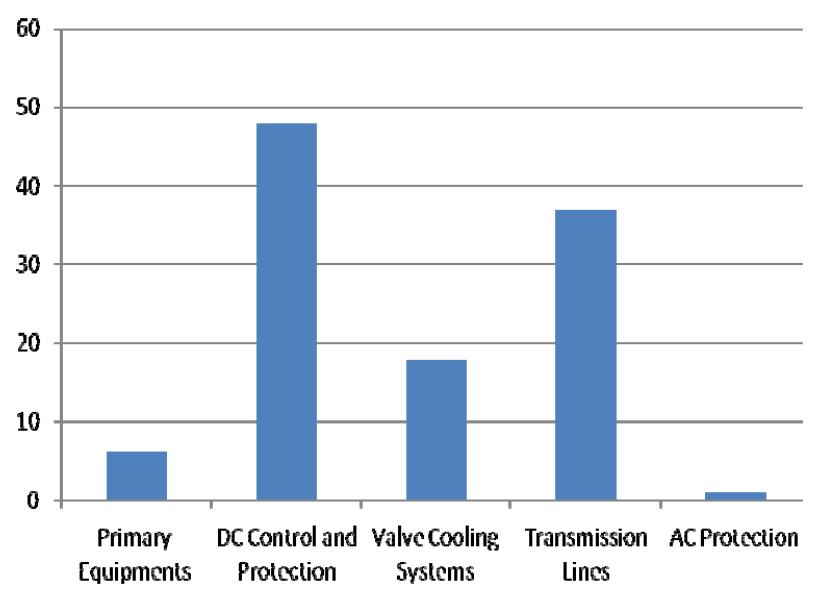

Figure 1. Number of Causes of DC Blocks in HVDC Systems.

\section{Reliability Strategies of DC control and Protection}

\subsection{High Resistance Fault Detection Using Broadband Fault Signal in HVDC Transmission Lines}

The acts of rejection of transmission line primary protection and fault location device caused by failure of high resistence happen occasionally. For example, a high resistance grounded failure happened in pole two in Gaozhao HVDC systems in July 8th, 2004, which led to the block of pole two. Another high resistence grounded failure happened in pole two in Tianguang HVDC system in May 15th, 2005.The fault location device didn't act in both two failures. [4,5] 
When high resistence fault happens in transmission lines, the reason why protection and location devices act insensitively or even reject action is that the signature information reflecting high resistence grounded fault is not obvious. Sampling frequency in existing transmission lines protection device is not more than $10 \mathrm{kHz}$, which is 0 to $5 \mathrm{kHz}$ in fact. And it's difficult to extract transient signature information because only simple signal processing algorithms like differential and integral are used. On the other hand, in order to guarantee enough high resolution of ranging, the sampling frequency in existing travelling wave location device is more than $1 \mathrm{MHz}$. But travelling wave location device limits the bandwidth of analog input signal to eliminate the disturbance of high frequency. The passband of analog filter circuit is 5 to $100 \mathrm{kHz}$. So it's difficult for the existing transmission lines protection device and travelling wave location device to effectively detect high resistence fault. [6-8]

To solve the problem of high resistence fault detection, the most effective way is to extract the subtle transient feature information. HVDC transmission lines high resistence fault detection uses broadband fault information which is 0 to $500 \mathrm{kHz}$ and requires that the sampling frequency of the device should be high enough and a fault transient feature extraction algorithm should be constructed. [9] On account of the problem of rejection of transmission lines protection and travelling location device when high resistence fault happens, some solutions are proposed as follow.

1) For a certain resolution of location device, the broader the frequency band is, the less the location result is affected by tansition resistence. When location device resolution and frequency band is rather high, the impact of transiton resistence on ranging result is eliminated basically, which effectively solve the problem of big error in location under the condition of high resistence fault.

2) Based on the broadband and high resolution, it can be known that wave velocity is only related to fault position. According to different fault positions, adopting different wave velocity which corresponds to different frequency component to calculate distance is an effective way to solve the problem of impact of fault position on wave velocity.

3) According to different features of maximum of noisy singal and fault wave singular point under the wavelet transform, the accurate detection of fault wave head can be realized. According to different resolution and different features of fault waveform, singular point can be calculated accurately by corresponding methods.

4) The broadband fault information and DC travelling wave location based on wave velocity optimization algorithm can be applicated into monopole single end, monopole double end, bipolar single end and bipolar double end fault location. It can improve the location accurance's adaptability for different fault distance and robustness of transient resistence.

\subsection{High Voltage Direct Current Filter Modeling and Fault Simulation Based on PSCAD-EMTDC}

Since Gaozhao and Xingan HVDC system went into operation, there were problems that DC filter quited operation or even caused system block.The DC filter protection of Anshun converter station has acted 10 times since 2004, where capacitor $\mathrm{C} 1$ unbalance protection acted 8 times.

A model of DC filter is constructed by electric magnetic simulation program PACAD-EMTDC. It could be used to detect fault, simulate faults in DC filter and analyze fault features. The model construction is showed as Figrure 2.

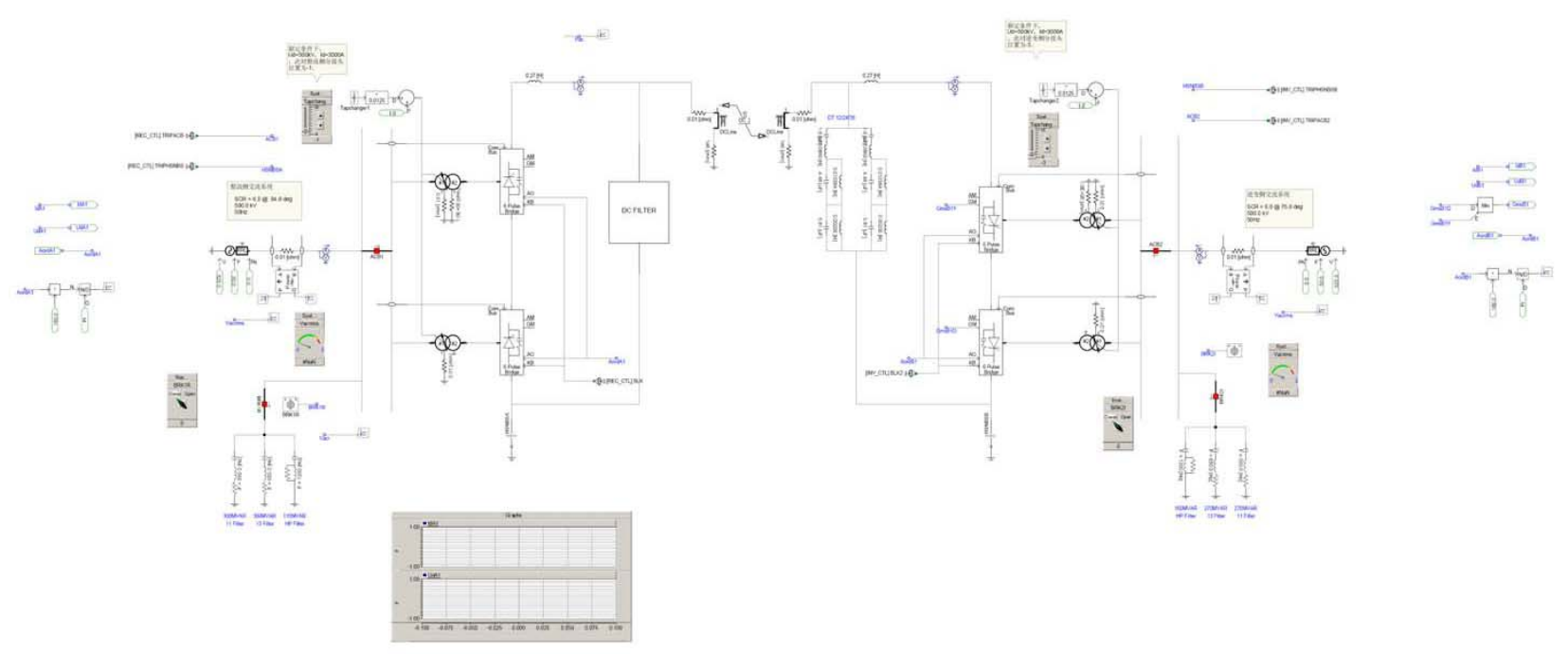

Figure 2. Construction of HVDC DC Filter Mode based on PSCAD-EMTDC. 
Table 2. Degee of Unbalance of C1 Capacitor for different number of capacitor faulted.

\begin{tabular}{cccc}
\hline $\begin{array}{c}\text { Number of } \\
\text { Faulted Capacitor }\end{array}$ & $\begin{array}{c}\text { Degree of } \\
\text { Unbalance }\end{array}$ & $\begin{array}{c}\text { Number of Faulted } \\
\text { Capacitor }\end{array}$ & $\begin{array}{c}\text { Degree of } \\
\text { Unbalance }\end{array}$ \\
\hline 1 & 0.016 & 8 & 0.197 \\
2 & 0.034 & 9 & 0.24 \\
3 & 0.053 & 10 & 0.291 \\
4 & 0.075 & 11 & 0.351 \\
5 & 0.1 & 12 & 0.426 \\
6 & 0.128 & 13 & 0.518 \\
7 & 0.16 & & \\
\hline
\end{tabular}

It's proposed that instantaneous value IR11/IT1 which directly reflects capacitor unbalance could be used as a criterion for C1 unbalance protection This improvement can effectively avoid abnormal jump of C1 capacitor unbalance protection on differential current. When C1 capacitor breaks down, the $\mathrm{C} 1$ protection can act right aiming at different types of faults. It has better reliability and sensitivity.

\subsection{Melting Ice Using Two Ends Back to Back Operation Mode}

The icing of transmission lines in winter is a nature disaster to power system, which threats the safe operation of power system. It brings mechanical damage to wires, towers and other metallic devices, which may breaks lines, pushes down towers and causes power failure. [10]

In 2008 disastrous weather of low temperature, rain, snow and ice impacted on southern area of China, causing huge economic losses that transmission lines broke down for long time on a large scale in Guizhou, Guangdong, Yunnan, Guangxi province. According to statistics, there are 36740 lines broken, 2018 substations outage and 8381 towers pushed down during this period. It's necessary to add operating mode of icing to control and protection system in HVDC systems which are vulnerable to icing weather.

When the load is low in dry season or the system comes to a stop as planned, the direct current is low so that problems of icing appear on transmission lines. [11] Designing icing lines protection function of DC two ends back to back operation mode in DC control protection system can satisfy the needs of lines protection in the period of low load in dry season.

DC two ends back to back operation mode means that in the period of icing weather, while a pole operates in rectifier mode transferring positive power, another pole operates in inverter mode transferring negative mode. [12] In this mode the power transferring direction of two poles is opposite while two poles can operates with a relatively larege power.The total transferring power is relatively low which is fit for the condition of low load in dry season.Loop current would be formed to produce DC loss to melt the ice.

The alternating system is affected less in DC two ends back to back operation mode that it's not necessary for alternating system to provide source for large load and reactive-load compensation equipments in converter stations can be in balance with the ones in alternating system.[13]

\section{Reliability Technique for Weak Links of Valve Cooling System}

According to the statistics of fault, exceptions and experience of maintainence since Guangzhou, Zhaoqing and Baoan converter stations was in operation, there are some weak links in valve cooling systems in these stations, which may cause unbanlance of DC system or even DC blocks.

No redundancy for valve cooling system sensor is an important reason why valve system may be blocked by error. Exceptions of single configuration may cause data which are sent to valve cooling control system changes so that DC system is blocked by error.Some measures are proposed in this papaer as follow to avoid this situation.

1) It's better to add an expansion water gauge for water tank to create redundancy and compare the values of two sensors to choose a better one. The function of stopping primary pump should be cancelled and the water gaouge added shoud be linked with the other one so that operation workers can observe water level of expansion water tank when patrolling and judge whether the control data transferred to sensor is abnormal or not.

2) A water supply sensor can be added to create redundancy which can be an electronic or thermoelectric one to make it easy for operators to realize the actual temperature of internal cooling water.The values of two sensors should be compared and hot water temperature can be a useful criterion to avoid mistakes.

3) The differential pressure of two adjacent valve towers can be used to create redundancy that it alarms when one sensor's differential pressure is low and it trips when the two sensors' differential pressure are both low.

\section{Conclusions}

This paper count the reliability data in late years and proposes some measures to improve operation reliability according to some faults happen in HVDC systems lately.

Xingan HVDC system went into operation in 2008 while Chusui HVDC system went into operation in 2010.So DC block times rose in according year. It's obvious that after many years' experience of operation in HVDC systems and measures of improving reliability are taken, time of DC blocks descents year by year and operation reliability in HVDC systems are improved. 


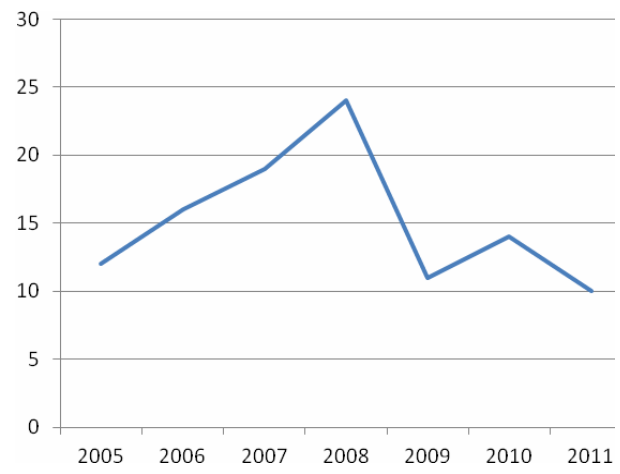

Figure 3. Time of DC Blocks in HVDC System During 2005 to 2011.

\section{Acknowledgements}

The authors gratefully acknowledge the support of National High-tech R\&D Program (863 Program) (2012A A050209) and China Southern Power Grid EHV Transmission Company Science and Technology Project.

\section{REFERENCES}

[1] W. J. Zhao, "HVDC Transmission and Transformation Engineering Technology,” China Electrical Power Press, Beijing, 2004.

[2] Y. L. Li, Y. P. Yang and N. Li, "Reasearch on Redundangcy Reliability of HVDC Control and Protection System," Power System Protection and Control, Vol. 16, No. 8, 2009, pp. 59-62.

[3] M. X. Wang, "Discuss about Open Line Test Theory in HVDC Systems,” Power System Technology, Vol. 28, No. 22, 2004, pp.1-5.

[4] X. L. Jiang, J. H. Yuan and C. X. Sun, "China $\pm 800 \mathrm{kV}$
UHVDC Transmission Line Outer Insulation Problems," Power System Technology, Vol. 30, No. 9, 2006, pp. 3-11.

[5] L. Zhao, P. Li and G. Q. Bu, "Yunnan - Guangdong \pm 800kV HVDC Systems Dynamic Equivalence Research," Power System Technology, Vol. 30, No.16, 2006, pp. 10-14.

[6] J. H. Zhang, "Reliability Research of Sanchang HVDC System," China Electric Power Research Institute, 1996.

[7] L. W. Jia, J. F. Jiang and X. Z. Hu, "2002 China HVDC Systems Operation Reliability Profiles,” Power Equipments, Vol. 5, No. 6, 2004, pp. 68-71.

[8] C. S. Wang and X. S. Zhou, "Fault Analysis of VBE Systems in Guiguang I Circuit Transmission System,” Vol. 5, No. 2, 2011, pp. 34-36.

[9] M. Ni, J. D. McCalley, V. Vittal, et al., “Online risk-based security assessment," IEEE Trans on Power Systems, Vol. 18, No.1, 2003, pp. 258-265.

[10] L. Q. Zhang, J. Q. Zhou, K. Y. Liu, et al., "HVDC Systems Index Statistics Analysis,” Power System Automation, Vol. 31, No.19, 2007, pp. 95-99.

[11] G. Asplund and A. Williamson, "A Novel Approach to Providing on Route Power Supplies to Rural and Urban Communities in Close Proximity to the Extra High Voltage DC Transmission Line," in Proceeding IEEE Power Engineering Society Power Africa Conference Exposition, 2007, pp. 1-6. doi: 10.1109/PESAFR.2007.4498119

[12] V. G. Agelidis, G. D. Demetriades and N. Flourentzou, "Recent Advances in High-voltage Direct Current Power Transmission Systems," Proceedings of National Power Electronics Conference of China, Xi' an, 2006, pp. 23-26.

[13] R. Leelaruji, J. Setr 'eus, L. Bertling and G. Olguin, "Availability Assessment of the HVDC Converter Transformer System," the 10th International Conference on Probabilistic Methods Applied to Power System (PMAPS), Puerto Rico, 2008. 